\title{
Contributing Factors to Student Engagement: An Implementation of JD-R model in Indonesian context
}

\author{
Rahmat Muhammad ${ }^{1}$, Ashry Sallatu ${ }^{2}$, Nur Akmal $^{3}$, Elvita Bellani $^{4}$ \\ \{rahmatmuhammad131@gmail.com¹, gegosallatu@gmail.com²,12akmalkemal@gmail.com³ \\ elvita.bellani@gmail.com ${ }^{4}$ \}
}

Department of Sociology, Universitas Hasanuddin, Jl. Perintis Kemerdekaan KM. 10 Makassar, Indonesia ${ }^{1}$, Department of International Relations, Universitas Hasanuddin, Jl. Perintis Kemerdekaan KM. 10 Makassar, Indonesia ${ }^{2}$, Department of Psychology, Universitas Negeri Makassar, Jl. Mappala No. 1 Makassar, Indonesia ${ }^{3}$, Department of Psychology, Universitas Hasanuddin, Jl. Perintis Kemerdekaan KM. 10 Makassar, Indonesia ${ }^{4}$

\begin{abstract}
Student engagement has been empirically proven contribute to academic achievement and individual well-being. However, only limited studies have examined contributing factors to student engagement, especially in Indonesia. This study aims to explore factors that contribute to student engagement in Indonesia there were 120 students aged 18-21 years participated in this study. An open-ended questionnaire was employed to collect data. The approach used to analyze data was thematic qualitative analysis. Categorization process was carried out in stages, starting from applied code to response, then categorize code to categories and subcategories, lastly, to summarize categories to more general categories, which are themes. The result of this research showed there were three resources that contribute to student engagement which are university resource (44\%), personal resource $(40 \%)$, and external resources besides the university $(16 \%)$. The results of this study differ from the theoretical models of student engagement which propose that resources only consist of university resources and personal resources. Implications and future research are discussed.
\end{abstract}

Keywords: Student Engagement; Job Resources; Personal Resources; Indonesia

\section{Introduction}

Student engagement refers to the level of student involvement which is characterized by positive affect, high energy, persistency in investing time and cognitive resource in academic and nonacademic activities [1], [2]. As consequences, they are more likely to have a better academic performance, also acquire more skills and knowledge which are necessary in their future career life [1],[3],[4]. Furthermore, since engaged student experience positive emotions, they are more likely to experience life satisfaction, and positive identification to their university [5], [6]. Taken all together, student engagement not only benefiting students, but also positively contribute to the achievement of university's vision and mission, and even to the attainment of national education goals.

Student engagement is similar to work engagement as the former also consist of demands that require constant physical and psychological efforts such as exam, writing 
assignment and class participation [7]. Fortunately, student also has resources, both personal resource and university resource which can be utilized to overcome these academic demands. Therefore, student engagement mechanism can be explained by adopting a theory which explain engagement at work, which is Job Demands-Resource Theory (JD-R). Accordingly, each job consist of stress process and motivational process [8]. Stress processes occur when individuals are faced by high demands and are not supported by sufficient resources to overcome them. Conversely, motivational process take place when the individual has sufficient resources, regardless of demand, which result in engagement. Therefore, to increase engagement, what needs to be done is to increase resources, not to reduce demands.

Considering the important contribution of resources to student engagement, it is very important to identify resources needed by students. On the other hand, the resources needed are highly dependent to how the resources are valued which are strongly influenced context, culture and time frame [9]. Hence, the resources needed are very context dependent. There are numerous study on contributing factors to student engagement [7], [10], [11]. However, to the best of our knowledge there are very limited research on student engagement in Indonesia. This study aims to explore the resources needed by students based on student's need perception on how to overcome academic demands in Indonesia.

\section{Research Method}

There were 120 students of Universitas Hasanuddin aged 18-21 years consist of men and women who participated in this study. Data were collected using an open-ended questionnaire. At the beginning of the questionnaire, there were explanation regarding student engagement characteristics and informed consent. Three questions were employed to ask participants about contributing factors to student engagement which are:

1. In your opinion, explain factors from your university that contribute to your engagement.

2. In your opinion, explain factors from yourself that contribute to your engagement.

3. In your opinion, explain other factors that have not been mentioned above, that contribute to your engagement.

Data were analyzed using thematic qualitative analysis approach [12] which consist of stages as follow:

- Data preparation. At this stage, data from collected questionnaire were typed and read carefully. There were 535 responses obtained. From these responses, 79 responses from 53 people were deleted because 49 responses were empty, and the others were irrelevant.

- First cycle coding

Each response was read carefully to decide the code used. Code are label given by coder that represent symbolic interpretation of the data. There were five coder who are divided into three separate groups. After all the data were coded, all coder met to discuss codes they have been made

- Second cycle coding

Coders were back to their groups. Each of groups worked to organize codes into categories and sub categories. After all codes were organized, all coders met and 
decided the categorization and subcategorization. Then, all coders summarized categorization and subcategorization into general theme.

\section{Result and Discussion}

Thematic qualitative analysis show that in general, there are three resources that contribute student engagement, which are university (44\%), personal resource $(40 \%)$ and external resources outside university $(16 \%)$. More specifically the results of the thematic analysis can be seen in the table below

Table 1. Thematic Qualitative Analysis

\begin{tabular}{lll}
\hline Theme & Categories & Total $\mathbf{( \% )}$ \\
\hline University & Learning facilities and infrastructures & $72(35,6)$ \\
Resource & Academic staff & $34(16,8)$ \\
& Learning paradigm & $23(11,4)$ \\
& Academic atmosphere & $21(10,4)$ \\
& Student activities & $21(10,4)$ \\
& Academic activities & $11(5,4)$ \\
& Financial support & $5(2,5)$ \\
& Senior students & $5(2,5)$ \\
& Information availability & $4(2,0)$ \\
& University regulation & $3(1,5)$ \\
Personal & Other non-academic activities & $3(1,5)$ \\
Resource & Psychological needs & $62(34,3)$ \\
& Personal quality & $31(17,1)$ \\
& Supportive behavior & $30(16,6)$ \\
& Personal motivation & $24(13,3)$ \\
& competence & $15(8,3)$ \\
& Positive affect & $11(6,1)$ \\
External & Responsibility & $8(4,4)$ \\
resource & Peers & $43(57,3)$ \\
outside & Parents & $16(21,3)$ \\
university & Family & $7(9,3)$ \\
& Off campus activitis & $4(5,3)$ \\
& Supportive environment & $3(4,0)$ \\
& Social Media & $1(1,3)$ \\
& God & $1(1,3)$ \\
\hline
\end{tabular}

As can be seen in Table 1, prevailing responses in university resources are learning facilities and infrastructure, followed by lecturers and learning paradigm. Typical responses are:

"Comfortable classroom"

"Laboratory to support experiments and research"

"Access to learning from internet" 
"Competent academic staff"

"Motivation and opportunity provided by academic staff"

"Learning methods applied increase classroom participation"

"Student Centered Learning stimulate student exploration"

"Implementation of Student-Centered Learning"

The next category is personal resources. In this category, the prominent resources are psychological needs, personal quality and supportive behavior. Some typical responses in this category are:

"Gain experience while learning to be a better person"

"To be useful to others"

"Willingness to grow and to learn"

"High curiosity and self-development"

"Not easily give up"

"Involved in every practicum process in the laboratory"

"Participate in academic activities on campus"

"Follow academic activities that have been determined"

The last category is external resources outside the university. In this category, popular response are peers, parents, and family. In this category, common responses are:

"I Want to make my parents proud of me"

"Support from family and closest friends"

"High support from parents and family"

"My parents demand me to give best academic achievement"

"Friends and friendly environment"

"I feel comfortable because my friends come from the same regions "

"Supporting friends"

In addition, Table 1 also shows that some results are consistent with JD-R [2]. Accordingly, resources used to overcome demand consist of job resources and personal resources. Job resources are physical, social and organizational aspects that can reduce negative consequence of utilization of physical and mental effort, help meet demands, and stimulate self-development [12], [13]. In this research, prominent job resources obtained from universities are the availability of adequate facilities and infrastructure, competent and supportive teaching staff, and a learning paradigm that stimulates learning.

Personal resources are aspects of the individual that make individuals feel that he/she can control and influence their environment [14]. In this study, predominant personal resources are the academics demands which are consistent with fulfillment of psychological needs, personal quality that can reduce demands, and behavior directed to meet academic demands. Occurrence of psychological needs as one of the resources also shows consistent results with selfdetermination theory that proposes individuals will be motivated and engage in activities that can meet their basic psychological needs [10], [15].

The emergence of the third theme which is external resource outside university shows that JD-R cannot be fully applied to the world of education, especially on the subject of this study. In other words, university resources and personal resources are not the only resources that contribute to student engagement. instead, there are also other resources, which are external resources outside university. In this category, the predominant categories are support from peers, parents, and family. This result shows that students are not isolated from the environment outside the university. In fact, university resources, personal resources, and external resources outside university synergized in contributing to student engagement. 
Friends, parents and family. The results of this study indicate that peers play an important role in student engagement. Peer resources are supportive friends, which helps meet academic demands, and provides comfort and happiness. This is consistent with Self Determination Theory which proposes that individuals have basic needs to care and be cared for by others [15]. Individuals will be intrinsically motivated be involved in activities that can meet these needs. Therefore, when university provide supportive friendship environment, they are motivated and persistent to participate in academic activities.

This study also shows an interesting result indicating the important role of parent and family in student engagement. It shows that parents and families continue to play an important role in children's education, even in adolescents and early adults. These parents and family resources contribute through two processes. Firstly, parents and families provide support for student's academic and non-academic activities which results in higher engagement. Next, parent also serve as demands of which students feel responsible to achieve good academic results, which can give a feeling of pride to their parents, and set a good example for their younger siblings. This result is in line with previous studies which propose that individuals with highly involved parents are more likely to achieve student engagement [16]. Furthermore, strong relationships between children and parents also not only provide support for children but also develop a sense of responsibility [17]

The results of this study are also in line with local values in the Makassarese and Buginese tribal. In Makassarese and Buginese tradition, there are value of sipakatau, sipakainge, sipakalebbi. These three values refer to mutual humanizing, mutual reminder, and mutual respect. These values are the basis for behaving towards elder people, peers and also younger people [13]. Through this relationship, Individuals not only receives support from those around them, such as families, friends and parents, but at the same time, individual is also responsible to return the favor and thus result in respect and respectful relationships.

Implications. This study identifies resources necessary for student engagement. Since student engagement significantly contributes to academic achievement and personal well-being also the attainment of university and national education goals, it is very important for university and other parties to create an education that can student engagement through fulfillment of relevant resources. Based on this study theses resources are university resources, personal resources and external resources outside university.

This research was approached by qualitative method to identify significant resources that contribute to student engagement. Therefore, prudent consideration is necessary for the generalization of the results of this study. It should be considered that meaningful resources are strongly influenced by personal judgments, which are strongly influenced by cultural context and time frame [19].

In addition, this study employed open-ended questionnaire to collect data. This method closes the possibility for researchers to clarify the participants responses. Thus, although this research can identify the significant resources contribute to student engagement, the mechanism behind it is remain unknown. Further studies need to be done to test this research quantitatively for better generalization, and to examine the mechanism student engagement

\section{Conclusion}

In conclusion, this present study aims to implement JD-R model in explaining student engagement in Indonesia. The results of this study show that JD-R is partially fit to explain 
student engagement. The availability of university resource and personal resource are not enough to develop engagement. Instead, there are other factors that also play an important role in student engagement, which is the external resources outside the university.

Acknowledgements. This study was funded by Minister of Higher Education, Research and Technology Decentralization fund under Basic Research Unhas scheme. Authors are grateful for high support from the Hasanuddin University Research and Community Service institution.

\section{References}

[1] W. B. Schaufeli, I. M. Martínez, A. M. Pinto, M. Salanova, and A. B. Bakker.: Burnout And Engagement In University Students A Cross-National Study (2002)

[2] A. B. Bakker and E. Demerouti.: Towards a model of work engagement Career Dev. Int (2008)

[3] G. D. Kuh.: What student affairs professionals need to know about student engagement, J. Coll. Stud. Dev (2009)

[4] G. D. Kuh, T. M. Cruce, R. Shoup, J. Kinzie, and R. M. Gonyea.: Unmasking the effects of student engagement on first-year college grades and persistence, J. Higher Educ (2008)

[5] V. Trowler and P. Trowler.: Student engagement evidence summary (2010)

[6] A. D. Lewis, E. S. Huebner, P. S. Malone, and R. F. Valois.: Life Satisfaction and Student Engagement in Adolescents, J. Youth Adolesc (2011)

[7] M. Salanova, W. Schaufeli, I. Martínez, and E. Bresó.: How obstacles and facilitators predict academic performance: the mediating role of study burnout and engagement Anxiety, Stress Coping, 2012 Vol. 23.pp. 53-70 (2010)

[8] W. B. Schaufeli.: Applying the Job Demands-Resources model A 'how to' guide to measuring and tackling work engagement and burnout Organ. Dyn (2017)

[9] S. E. Hobfoll.: Conservation of Resources A New Attempt at Conceptualizing Stress. Am. Psychol (1989)

[10] V. Trowler.: Student engagement literature review (2010)

[11] J. Reeve.: A self-determination theory perspective on student engagement in Handbook of Research on Student Engagement (2012)

[12] M. B. Miles, A. Michael Huberman, and J. Saldaña.: Qualitative data analysis: A methods Sourcebook (3rd Edition) (2014)

[13] S. Buchori and N. Fakhri.: Nilai-Nilai Kedamaian Dalam Perspektif Suku Bugis dan Makassar. JOMSIGN J. Multicult. Stud. Guid. Couns (2018) 